\title{
Class-E Rectifiers and Power Converters
}

\author{
José A. García ${ }^{1}$ and Zoya Popović ${ }^{2}$ \\ ${ }^{1}$ Department of Communications Engineering, University of Cantabria, 39005 Santander, Spain \\ ${ }^{2}$ Department of Electrical, Computer and Energy Engineering, University of Colorado, Boulder, CO, 80309, U.S.A.
}

\begin{abstract}
This paper reviews the use of the class-E topology for RF-to-DC and DC-to-DC power conversion. After covering its early history, the class-E rectifier is introduced in the context of the time-reversal duality principle, to be then integrated with an inverter in a class- $\mathrm{E}^{2} \mathrm{DC} / \mathrm{DC}$ converter. Recent examples and applications at UHF and microwave bands are finally presented. A review of RF rectifiers based on Schottky diodes or FET transistors, is followed by a discussion of synchronous and self-synchronous implementations of the double class-E DC/DC converter, using advanced GaN HEMT transistors.

Index Terms - Class-E, DC/DC power conversion, microwave, resonant converters, rectifiers, soft switching, UHF.
\end{abstract}

\section{INTRODUCTION}

In the 80 's, the interest in reducing the value and size of reactive components moved power supply specialists to operate $\mathrm{DC} / \mathrm{DC}$ converters at hundreds of $\mathrm{kHz}$ or even $\mathrm{MHz}$ frequencies. Motivated by the advantages this could offer in terms of miniaturization and improved control bandwidth, they had to face the frequency-dependent turn-on and turn-off losses associated with the use of rectangular waveforms in the hardswitched topologies of that time. Similar to RF/microwave power amplifiers (PAs), the introduction of resonant circuits allowed shaping either a sinusoidal voltage or current, offering the opportunity for high efficiency operation and giving rise to resonant converters [1]. Obtained by cascading a DC/AC resonant inverter with a high-frequency rectifier, a resonant converter first transforms the DC input power into controlled AC power, to then convert it back into the desired DC output.

\section{Class-E AMPLIFIER AS POWER INVERTER}

Originally conceived as a class-E RFPA [2], the idea of using a class-E topology for zero voltage (ZVS) and zero voltage derivative switching (ZVDS) in the inverting side of a resonant power converter is attributed to Gutmann [3]. A deeper insight into its operation was later provided in seminar papers such as [4], with the contribution of Nathan O. Sokal. Referred to as a class-E converter, impressive efficiencies about $80 \%$ were measured for the 40-W 1.5-MHz circuit in Fig. 1, using the International Rectifier IRF 150 MOSFET as the power switch. The experimental converter was designed and built with much less difficulty than had been expected by the authors [4], suggesting the class-E topology was well-suited to this application. Many subsequent examples of its use as inverter may be found in the literature, including also variants of the original topology, currently considered as part of a continuum of class-E modes.

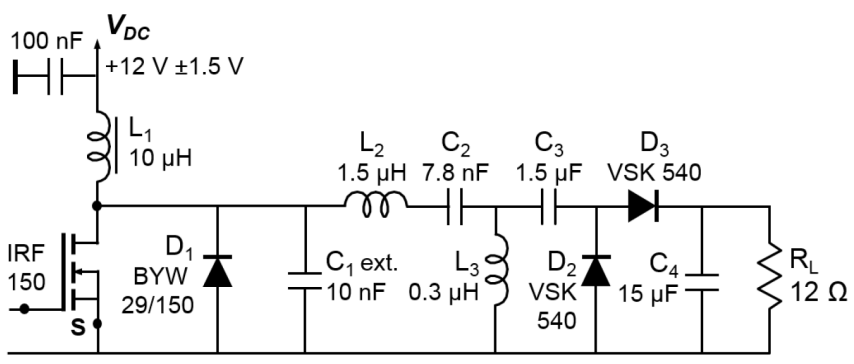

Fig. 1. Schematic of the experimental converter in [4] (driver not included).

Implementations at HF and VHF bands have become common, where solutions based on the class- $\Phi_{2}$ inverter may be highlighted [5] for their high-efficiency and low-voltage stress performance. At microwave frequencies, a low-power $64 \%$ efficient 4.6-GHz planar converter combining a GaAs MESFET class-E PA and a Schottky diode rectifier was demonstrated as early as 1999 [6].

\section{Class-E ReCTIFIER AND Class-E ${ }^{2}$ DC/DC CONVERTER}

\section{A. Time Reversal Duality}

Any resonant amplifier may be transformed into a resonant rectifier of the same operating class through the time reversal (TR) duality principle, as discussed first in [7]. According to this principle, the rectifier switch voltage and current waveforms are time-reversed versions of the corresponding switch waveforms in the inverter:

$$
v_{R}(t)=v_{I}(-t) \text { and } i_{R}(t)=-i_{I}(-t)
$$

leading to a simple relation between their instantaneous powers:

$$
p_{R}(t)=v_{R}(t) \cdot i_{R}(t)=-v_{I}(-t) \cdot i_{I}(-t)=-p_{I}(-t)
$$

Averaged over a cycle, the mean powers in these dual networks have opposite signs, meaning the direction of energy flow is reversed in the rectifier for the desired AC-to-DC conversion.

Based on the above, the class-E PA circuit in Fig. 2a transforms into the class-E rectifier in Fig. 2b. Analyzed in detail in [8], this is one of the many possible topologies, with rectification of active, or synchronous type, where the gate drive signal of the switching transistor needs to be synchronized with the $\mathrm{AC}$ excitation. Under $50 \%$ duty cycle operation and with the rest of assumptions from [2], the class-E PA in Fig. 2a is seen by its drain voltage supply as a DC resistance $R_{d c}=1 /\left(\pi \cdot \omega \cdot C_{p}\right)$. 
If a DC load of this value is at the output of the class-E rectifier, as in Fig. 2b, it presents a resistive input impedance to the $\mathrm{AC}$ source equal to the well-known nominal terminating condition, $R_{a c}=0.1836 /\left(\omega \cdot C_{p}\right)$.

a)

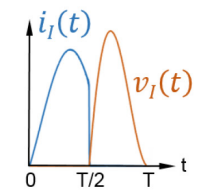

b)
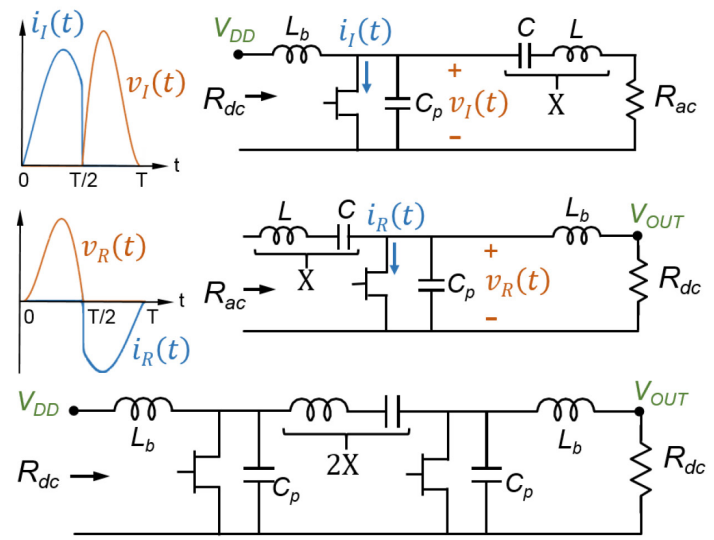

Fig. 2. a) The class-E inverter or PA, and b) its time-reversed dual, a classE synchronous rectifier. c) A basic class- $E^{2}$ DC/DC converter obtained when cascading a) and b). For operation at RF/microwave frequencies, the parallel capacitance $\left(\mathrm{C}_{\mathrm{p}}\right)$ is generally provided by the device output capacitance $\left(\mathrm{C}_{\text {out }}\right)$. Characteristic waveforms for the switch voltage and current are also shown in a) and b).

Although diode-based rectifier implementations are common, sufficiently fast Schottky diodes capable of handling high current and voltage levels are rarely available at UHF and higher frequencies, pointing to transistor-based rectifiers as the only choice for high-power RF-DC conversion at these bands.

\section{B. Class-E $E^{2}$ Resonant Converter}

The class-E rectifier was certainly conceived for the implementation of the double class-E or class- $\mathrm{E}^{2}$ resonant converter [9]. As depicted in Fig. 2c, when cascading the circuits in Fig. $2 \mathrm{a}$ and $2 \mathrm{~b}$, the rectifier provides the load resistance $R_{a c}$ required by the inverter. Therefore, both circuits may operate under the desired soft-switching conditions without additional circuit elements. For ideal lossless operation, the output DC voltage ( $V_{\text {OUT }}$ ) would equal $V_{D D}$.

Originally proposed with frequency-based output voltage control [9], the thinned-out method, the PWM and the phasebased techniques [10] are among other valid strategies for voltage regulation. Solutions may be found with oscillating inverters $[11,12]$ or in multiphase converters where two similar cells are interleaved [13]. While the synchronous operation of an active rectifier requires a second $\mathrm{AC}$ source to drive the gate of the transistor, self-synchronous operation is an attractive alternative for RF/microwave implementations. Relying on power coupled from the drain to the gate through the feedback capacitance, $C_{g d}$, and the use of a highly reflective termination at the gate $[12,14]$, the transistor may be turned on without a second source and with the same performance as that obtained for the optimum phase and amplitude of the synchronous drive signal, but with higher overall efficiency if the power of the drive signal is taken into account.

\section{RECENT EXAMPLES AND APPLICATIONS}

Class-E diode or FET-based rectifiers are finding interest for efficiently recovering power from an incident RF signal in wireless power transmission applications (WPT). For example, a recent synchronous rectifier in $0.13 \mu \mathrm{m}$ CMOS technology at $2.4 \mathrm{GHz}$ [15] is designed to be employed in wireless sensors that do not require batteries. However, most of rectifier reported use in the literature has been as part of the above double classE DC/DC power converter. Class- $E^{2}$ topologies with a rectifier wirelessly connected to the inverter are becoming common, at hundreds of $\mathrm{kHz}$ or a few $\mathrm{MHz}$, for implementing inductive or resonant WPT links [16].

\section{A. Class-E Rectifiers}

Two illustrative examples of class-E low-power rectifiers, for use in far-field WPT, are first described in this section. The class-E rectifier in Fig. 3a from [17] employs an Avago Tech. HSMS-282 Schottky diode. A peak efficiency value of $74 \%$ was measured at $23 \mathrm{dBm}$, with a recovered voltage linearly following the input amplitude (Fig. 3b). When the incident power is reduced, the variation in the input impedance affects the performance. An interesting solution to this limitation may come from the use of resistance compression networks and a plurality of similar rectifiers [18]. For very low input power levels, the signal excursion may not be sufficient for turning the diode on.
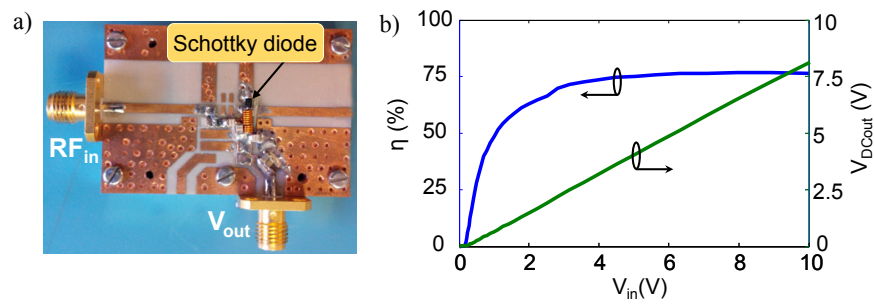

Fig. 3. Diode-based rectifier [17]: a) photograph and b) measured profile.

In Fig. 4, a photograph of a self-synchronous and self-biased rectifier is included, using the VMMK-1218 EpHEMT from Avago Tech. For turning on the device at very low power values, a sort of bootstrap connection of the rectified voltage to the gate terminal was proposed in [19]. The gate DC voltage may be also forced to follow the input power, thanks to an appropriately dimensioned biasing resistor and the small DC current resulting from rectification in the device gate-to-source junction. Measured results for $915 \mathrm{MHz}$ and $2.45 \mathrm{GHz}$ implementations show high peak efficiencies ( $88 \%$ and $77 \%$, respectively), with a reduction of only 10 points for a power range of $20 \mathrm{~dB}$.

High-power and efficient rectifiers are also feasible at UHF and microwave bands [14] with GaN HEMT technology. Single-ended single-stage, power combined and two-stage MMIC 
implementations at $\mathrm{X}$ band have been demonstrated with efficiencies up to $70 \%[20,21]$, at a few watt level, based on alternative operating classes, e.g. class $\mathrm{F}^{-1}$ or just generally harmonically-terminated PAs operated as rectifiers [22].

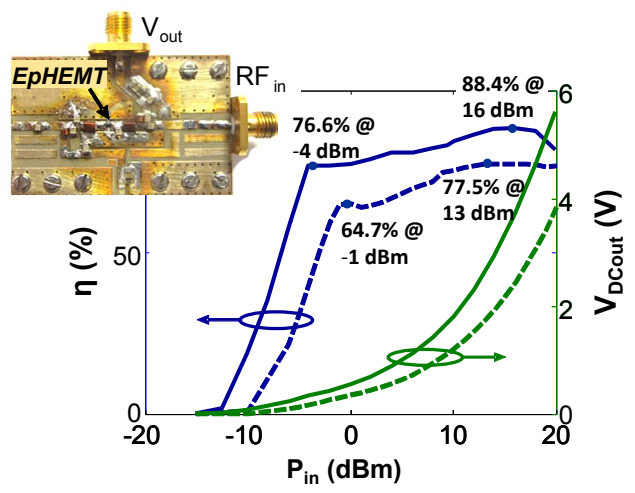

Fig. 4. E-pHEMT rectifier [19]: photograph and measured results for (一) $900 \mathrm{MHz}$ and (--) $2.45 \mathrm{GHz}$ implementations.

A promising design methodology for Class-E rectifiers with near resistive input impedance has been recently presented in [23]. Experimentally evaluated with Si Schottky diodes for VHF rectification, it may be perfectly valid for transistor-based topologies at UHF and the lower microwave bands.

\section{B. DC-DC Converters}

The examples below for UHF/microwave converters include both synchronous and self-synchronous rectifiers. The photograph and results in Fig. 5 correspond to a synchronous class$\mathrm{E}^{2}$ converter using CGH60030D GaN transistors from Wolfspeed, designed following the technique in [24]. With a peak of nearly $80 \%$, the efficiency is as high as $75 \%$ for $6 \mathrm{~dB}$ of power back-off. Conceived to be employed with FM-control as in $[9,24]$, it could be used as envelope modulator. Very fast dynamic performance was measured, with a large-signal bandwidth of $56.5 \mathrm{MHz}$ and a slew-rate $2.25 \mathrm{~V} / \mathrm{nS}$.

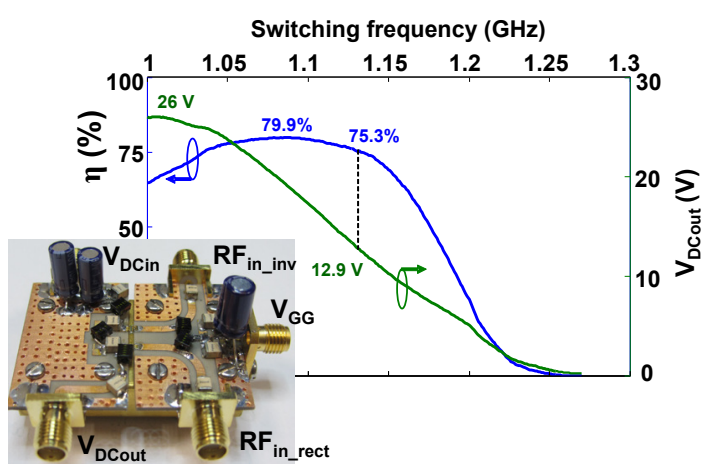

Fig. 5. Die-based GaN HEMT converter: photograph of the implementation together with the measured output voltage and drain efficiency profiles.

In Fig. 6a, a self-synchronous converter requiring only a single RF input, is presented [12]. Implemented with Qorvo 250$\mathrm{nm}$ GaN HEMT devices around $1.2 \mathrm{GHz}$, with a resonant dc- isolated coupling network between the PA and rectifier, 75\% total efficiency is demonstrated at $5 \mathrm{~W}$ (Fig. 6b). An oscillating self-synchronous DC-DC converter is also successfully demonstrated and tested in [12]. a)

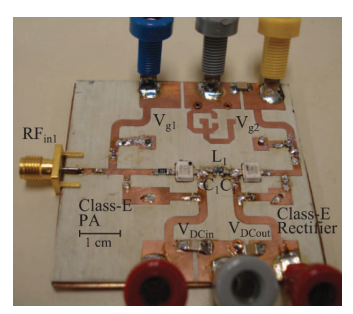

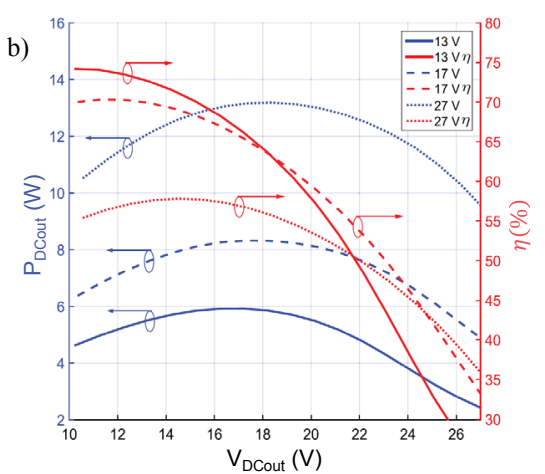

Fig. 6. Class-E ${ }^{2}$ self-synchronous DC-DC converter at $1.2 \mathrm{GHz}$ [12]: a) photograph and $b$ ) measured output power and efficiency profiles with $\mathrm{V}_{\text {DCout }}$.

The class- $\mathrm{E}^{2}$ architecture was also integrated in the Qorvo 150-nm GaN on $\mathrm{SiC}$ process at $4.6 \mathrm{GHz}$ in [25], with a decreased efficiency due to the increased switching losses expected at this frequency for this particular process. Nevertheless, this $2.3 \mathrm{~mm} \times 3.8 \mathrm{~mm}$ integrated converter is fully monolithic with no external magnetic components, Fig. 7. The total efficiency of around 50\% indicates that both rectifier and amplifier are operating at efficiencies above $70 \%$.

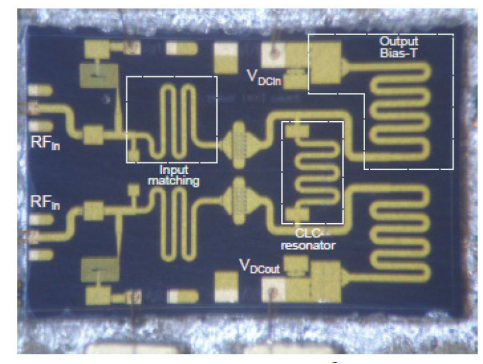

Fig. 7. Fully integrated class- $\mathrm{E}^{2}$ synchronous dc-dc converter at $4.6 \mathrm{GHz}$ [25].

\section{CONCLUSION}

The low-loss operation offered by the class-E topology, introduced worldwide to the RF/microwave community by $\mathrm{Na}$ than O. Sokal, has found significant application also for RF-toDC and DC-to-DC power conversion. Avoiding switching losses at high frequencies through a simple topology, it has become attractive either for high efficiency WPT rectifiers or mainly for high power density and fast response converters. The advances in high breakdown devices, such as GaN HEMTs, allow continuing improvements in class-E rectifiers and converters. 


\section{ACKNOWLEDGMENT}

This work was supported in part by the Spanish Ministry of Economy and Competitiveness (MINECO) under project TEC2014-58341-C4-1-R, co-funded with FEDER, and in part by the Advanced Research Projects Agency-Energy (ARPA-E), U.S. Department of Energy, under Award Number DEAR0000216 and the DARPA MPC program, ONR award N00014-11-1-0931.

\section{REFERENCES}

[1] M. K. Kazimierczuk and D. Czarrkowski, Resonant Power Converters, NJ: John Wiley \& Sons, 2011.

[2] N. O. Sokal and A. D. Sokal, "Class E, A New Class of High-Efficiency Tuned Single-Ended Switching Power Amplifiers," IEEE J. Solid-State Circ., vol. SC-10, pp. 168-176, June 1975.

[3] R. J. Gutmann, "Application of RF Circuit Design Principles to Distributed Power Converters," IEEE Trans. Ind. Electron. Control Instrum., vol. IECI-27, pp. 156-164, Aug. 1980.

[4] R. Redl, B. Molnár, and N. O. Sokal, "Class E Resonant Regulated DC/DC Power Converters: Analysis of Operations, and Experimental Results at 1.5 MHz," IEEE Trans. Power Electron., vol. PE-1, pp. 111-120, April 1986.

[5] J. M. Rivas, O. Leitermann, Y. Han, and D. J. Perreault, "A Very High Frequency DC-DC Converter Based on a Class $\Phi_{2}$ Resonant Inverter," IEEE Trans. Power Electron., vol. 26, pp. 2980-2992, Oct. 2011.

[6] S. Djukic, D. Maksimovic and Z. Popovic, "A Planar 4.5-GHz DC-DC Power Converter," IEEE Trans. Microwave Theory Tech., vol. 47, pp. 1457-1460, Aug. 1999.

[7] D. C. Hamill, "Time Reversal Duality and the Synthesis of a Double Class E DC-DC Converter," $21^{\text {st }}$ Power Electron. Specialist Conf., PESC'90, pp. 512-521, 1990.

[8] M. K. Kazimierczuk, "Analysis of Class E Zero-Voltage-Switching Rectifier," IEEE Trans. Circuits Syst., vol. 37, pp. 747-755, 6, June 1990.

[9] M. K. Kazimierczuk, J. Jozwik, "Resonant DC/DC Converter with ClassE Inverter and Class-E Rectifier," IEEE Trans. Ind. Electron., vol. 36, pp. 468-478, Nov. 1989.

[10] J. A. García, R. Marante and M. N. Ruiz, "GaN HEMT Class E² Resonant Topologies for UHF DC/DC Power Conversion," IEEE Trans. Microwave Theory Tech., vol. 60, pp. 4220-4229, Dec. 2012.

[11] H. Hase, H. Sekiya, Jianming Lu and T. Yahagi, "Resonant DC/DC Converter with class E oscillator," IEEE Int. Symp. Circuits Syst., pp. 720723, 2005.
[12] I. Ramos, M. N. Ruiz, J. A. García, D. Maksimovic and Z. Popovic, "GaN Microwave DC-DC Converters," IEEE Trans. Microwave Theory Tech., vol. 63, pp. 4473-4482, Dec. 2015.

[13] M. Katayama, H. Sekiya and T. Yahagi, "An Interleaved Class E ${ }^{2}$ DC/DC Converter," IEEE Int. Symp. Circuits Syst, pp. 2833-2836, 2008.

[14] M. Roberg, T. Reveyrand, I. Ramos, E. A. Falkenstein and Z. Popovic, "High Efficiency Harmonically Terminated Diode and Transistor Rectifiers," IEEE Trans. Microwave Theory Tech., vol. 60, pp. 4043-4052, Dec. 2012.

[15] S. Dehghani and Thomas Johnson, "A $2.4 \mathrm{GHz}$ CMOS Class-E Synchronous Rectifier," IEEE Trans. Microwave Theory Tech., vol. 64, pp. 16551666, May 2016.

[16] M. Liu, Y. Qiao, S. Liu and C. Ma, "Analysis and Design of a Robust Class E2 DC-DC Converter for Megahertz Wireless Power Transfer," IEEE Trans. Power Electronics, vol. PP, pp.1-11, 2016.

[17] L. Rizo, D. Vegas, M. N. Ruiz, R. Marante, L. Cabria and J. A. García, "Class-E Amplifier and Rectifier for a Wireless Link with Secure Signal and Simultaneous Power Transmission," 2016 IEEE Wireless Power Transfer Conference (WPTC), pp. 1-3, Aveiro, 2016.

[18] T. W. Barton, J. M. Gordonson and D. J. Perreault, "Transmission Line Resistance Compression Networks and Applications to Wireless Power Transfer," IEEE Journal Emerging Selected Topics Power Elect., vol. 3, pp. 252-260, March 2015.

[19] M. N. Ruiz and J. A. García, "An E-pHEMT Self-biased and Self-synchronous Class E Rectifier," IEEE MTT-S Int. Microw. Symp., pp. 1-4, 2014.

[20] M. Litchfield, S. Schafer, T. Reveyrand and Z. Popović, "High-Efficiency $\mathrm{X}$-Band MMIC GaN Power Amplifiers Operating as Rectifiers," IEEE MTT-S Int. Microw. Symp., pp. 1-4, 2014.

[21] M. Coffey, S. Schafer and Z. Popović, "Two-stage High-efficiency XBand GaN MMIC PA/ Rectifier," IEEE MTT-S Int. Microw. Symp., pp. $1-4,2015$.

[22] Z. Popovic, I. Ramos, T. Reveyrand and M. Litchfield, "Microwave Transistor Power Rectifiers and Applications," 2016 IEEE Compound Semiconductor Integrated Circuit Symposium (CSICS), Austin, TX, 2016, pp. $1-4$.

[23] J. A. Santiago-González, K. M. Elbaggari, K. K. Afridi and D. J. Perreault, "Design of Class E Resonant Rectifiers and Diode Evaluation for VHF Power Conversion," IEEE Trans. Power Electron., vol. 30, pp. 4960-4972, Sept. 2015.

[24] J. A. García, R. Marante, M. N. Ruiz and G. Hernández, "A 1 GHz Frequency-controlled Class E2 DC/DC Converter for Efficiently Handling Wideband Signal Envelopes," IEEE MTT-S Int. Microw. Symp., pp. 1-4, 2013.

[25] I. Ramos and Z. Popovic, "A Microwave Monolithically Integrated Distributed 4.6 GHz DC-DC Converter", IEEE MTT-S Int. Microw. Symp., pp.1-4, 2016. 